\title{
HISTÓRIA EM JEAN-JACQUES ROUSSEAU: A DECADÊNCIA SEM VOLTA
}

\author{
Priscila de Oliveira Silva ${ }^{1}$ \\ Luciano da Silva Façanha
}

Resumo: Desde o Discurso sobre as ciências e as artes, Rousseau nos aponta para uma história das sociedades, quando responde negativamente a pergunta da Academia de Dijon se o restabelecimento das ciências e das artes teria contribuído para o aprimoramento moral. No Discurso sobre a origem e os fundamentos da desigualdade entre os homens, o filósofo aborda a história da humanidade como uma história de decadência e degeneração, da qual é impossível retornar à natureza de origem. A corrupção das sociedades pode ser retardada, mas jamais revertida. Dito de outra maneira, Rousseau apresenta uma concepção linear da história, e o objetivo deste trabalho é apresentá-la à luz da interpretação de Maria das Graças de Souza.

Palavras-chave: história - sociedade - decadência.

A noção de história em Jean-Jacques Rousseau não poderia ser diferente do tom pessimista e condenatório que está presente em suas obras: a história de uma sociedade degenerada e corrompida. O filósofo genebrino distingue o homem primitivo do estado natural que vive em si mesmo, e o homem civilizado da sociedade civil que vive fora de si, pois está sempre considerando a opinião do outro. O homem da segunda descrição é o que descreve tão bem o do Século das Luzes, segundo Rousseau. Resta-nos agora entender qual o percurso da história da humanidade juntamente com essas duas noções de homem.

Maria das Graças de Souza em seu livro Ilustração e história: o pensamento sobre a bistória no Iluminismo francês dedica um capítulo, intitulado História e declínio em Rousseau, para verificar que tipo de história Rousseau aponta que seja a da humanidade. Ora, se a história da humanidade começa como história da inocência e se desenvolve como a história da queda, estaríamos condenados, indubitavelmente, à degeneração, ou, num momento de esperança, encontraríamos a redenção? Ou ainda, voltaríamos à origem? Para responder tais questões, é preciso refazer o próprio percurso histórico que Rousseau traçou.

É no Discurso sobre a origem e os fundamentos da desigualdade entre os homens que Rousseau situa o homem nas duas situações. Logo no início do Segundo Discurso, Rousseau anuncia que não tratará de verdades históricas, mas sim de raciocínios hipotéticos e condicionais para

\footnotetext{
${ }^{1}$ Mestranda do Programa de Pós-Graduação em Cultura e Sociedade (PGCult) - Mestrado Interdisciplinar da Universidade Federal do Maranhão - UFMA. Graduada em Filosofia. Conta com financiamento da Fundação de Amparo à Pesquisa do Estado do Maranhão (FAPEMA/CAPES) para o desenvolvimento de sua pesquisa. E-mail:prih.o@hotmail.com.

2 Doutorado em Filosofia pela Pontifícia Universidade Católica de São Paulo - PUC/SP. Professor do Departamento de Filosofia e do Programa de Pós-Graduação em Cultura e Sociedade da Universidade Federal do Maranhão - UFMA. E-mail: lucianosfacanha@hotmail.com.
} 
mostrar as coisas em seu estado natural, recurso utilizado por ele no qual podemos comparar os dois estados, e percebermos o quão longe estamos de nossa natureza, ao caminharmos em direção oposta a ela.

Sendo assim, temos, inicialmente, os homens selvagens, livres e inocentes que viviam dispersos, voltavam-se somente às verdadeiras necessidades, cuja Natureza era suficiente para atendê-las. Os únicos instrumentos que utilizavam eram seus próprios corpos, que, expostos às tempestades, mudanças de estações e outras forças que a Natureza produz, eram resistentes e preparados para enfrentar a situação mais difícil possível. Os homens civilizados, ao contrário, possuidores de tantos utensílios que tornavam suas vidas mais sofisticadas, eram imensuravelmente mais fracos. Comparando o homem selvagem e o homem civilizado, Rousseau questiona qual estado é mais vantajoso:

Se tivesse um machado, seu punho romperia galhos tão resistentes? Se tivesse uma funda, lançaria com a mão, com tanto vigor, uma pedra? Se possuísse uma escada, subiria a uma árvore tão ligeiramente? Se tivesse um cavalo, seria tão veloz na corrida? Dai ao homem civilizado o tempo de reunir todas essas máquinas à sua volta; não se poderá duvidar que, com isso, sobrepasse, com facilidade, o homem selvagem. Se quiserdes, porém, ver um combate mais desigual ainda, deixa-os nus e desarmados uns defronte dos outros, e logo reconhecereis qual a vantagem de sempre ter todas as forças à disposição (....). ${ }^{3}$

O estado no qual os homens se encontram nesse momento é o de pura inocência, vivendo dispersos na natureza, não há dependência mútua entre eles, havendo apenas a comparação em relação aos animais, pois "verificando que mais os ultrapassa em habilidade do que eles o sobrepujam pela força, aprende a não mais temê-los." ${ }^{\text {E }}$ é nesse estado também que esses "primeiros homens" têm quase como única preocupação a própria conservação e suas faculdades deverão ser exercitadas principalmente para esse fim, "seja o ataque e a defesa, quer para subjugar a presa, quer para defender-se de tornar-se a de um outro animal."

Até aqui, como observa Rousseau, o homem foi analisado em seu aspecto físico. É preciso agora considerá-lo numa perspectiva metafísica e moral para compreendermos em que sentido, mais uma vez, Rousseau julga a passagem do homem selvagem ao da sociedade, e como isso traz consequência em sua concepção de história.

Ao contrário do animal que não pode desviar-se do que a Natureza lhe impõe como regra, o homem, que é um agente livre, por um ato de liberdade, concorda ou vai para o caminho inverso do que a Natureza lhe dita. Aliás, há uma qualidade muito específica e

${ }^{3}$ ROUSSEAU, Discurso sobre a origem e os fundamentos da desigualdade entre os homens, p. 239.

${ }^{4}$ ROUSSEAU, Discurso sobre a origem e os fundamentos da desigualdade entre os homens, p. 239.

${ }^{5}$ ROUSSEAU, Discurso sobre a origem e os fundamentos da desigualdade entre os homens, p. 242. 
fundamental que distingue o homem do animal e é em grande parte responsável da trajetória humana rumo à decadência: é a faculdade de aperfeiçoar-se. Conforme Rousseau:

Seria triste, para nós, vermo-nos forçados a convir que seja essa faculdade, distintiva e quase ilimitada, a fonte de todos os males dos homens; que seja ela que, com o tempo, o tira dessa condição original na qual passaria dias tranquilos e inocentes; que seja ela que, fazendo com que através dos séculos desabrochem suas luzes e erros, seus vícios e virtudes, o torna com o tempo o tirano de si mesmo e da natureza. ${ }^{6}$

Como observa Souza, a ideia de perfectibilidade é um processo de desnaturação:

É preciso assinalar, em primeiro lugar, que a noção de perfectibilidade, componente inegável da ideia de progresso, tem um papel fundamental na antropologia de Rousseau. 'Qualidade muito específica', 'faculdade muito ilimitada', ela distingue o homem do animal, e, com a intervenção das circunstâncias, desenvolve sucessivamente as outras faculdades. Este processo de aperfeiçoamento é um processo de desnaturação. Para compreendê-lo, é preciso atentar para o tempo com a sua 'lenta sucessão das coisas', na qual a ação de pequenas causas, agindo sem cessar, produzirá as grandes revoluções. Assim, diz Rousseau no Segundo Discurso, para compreender melhor a história dos homens, 'é preciso seguir o progresso dos tempos e das coisas', estudar, 'no progresso das coisas as ligações escondidas que o vulgo não percebe’.

Como bem percebe a autora, a ideia dessa continuidade histórica serve, para Rousseau, não para afirmar o progresso da humanidade, mas para criticá-la. O pessimismo sobre o "progresso" da humanidade se dá em dois sentidos. Em primeiro lugar, podemos considerar que o homem progrediu ao dormir em cabanas se protegendo das intempéries da natureza. Porém, esse progresso também significa fraqueza, pois, se antes os homens viviam em comunhão com a natureza, ao ponto de adaptarem-se às circunstâncias mais perigosas, ao tentar desviá-las de si, menos as suportarás.

Esse "anti-progresso" não consiste apenas no aspecto material, mas sobretudo nas relações sociais. Se, antes, a primeira preocupação do homem era apenas com sua própria conservação, e a Natureza era suficiente para satisfazer todas as suas necessidades (como dormir, comer, relações sexuais), não existia dependência mútua entre os homens. Mas, à medida que o gênero humano cresceu, e "anos estéreis, invernos longos e rudes, verões

${ }^{6}$ ROUSSEAU, Discurso sobre a origem e os fundamentos da desigualdade entre os homens, p. 243.

7 SOUZA, Ilustração e história: o pensamento sobre a história no Iluminismo francês, p. 77. 
escaldantes, que tudo consomem, exigiram deles uma nova indústria", os homens começaram a compararem-se entre si, causando uma espécie de reflexão de quem era mais forte ou fraco, mais lento ou rápido, mais ousado ou medroso.

Souza ressalta que ao deixar a vida solitária e nômade nas florestas pela vida familiar, o homem passou a experimentar sentimentos de ternura, paternais e maternais, e o amor conjugal. Além disso, a divisão de trabalho trouxe uma relação de dependência que antes os homens não haviam experimentado, "o ferreiro precisa do agricultor, o agricultor do pastor. Ninguém é mais auto-suficiente."

Dessa nova configuração de convivência desenvolvem-se novos progressos, como o estabelecimento das famílias, tornando-se pequenas sociedades, a formação de um idioma comum, as ideias de mérito e de beleza, ocasionando os sentimentos de preferências. É no momento que os homens começaram a apreciar-se mutuamente que se estabeleceu a ideia de consideração. Aqui, é o amor-próprio se instalando entre os homens. Diz Rousseau:

Cada um começou a olhar os outros e a desejar ser ele próprio olhado, passando assim a estima pública a ter um preço. Aquele que cantava ou dançava melhor, o mais belo, o mais forte, o mais astuto ou o mais eloquente, passou a ser o mais considerado, e foi esse o primeiro passo tanto para a desigualdade quanto para o vício; dessas primeiras preferências nasceram, de um lado, a vaidade e o desprezo, e, de outro, a vergonha e a inveja. ${ }^{10}$

Essa fatal condenação se revela muito mais nociva na época na qual Rousseau se encontra. No Discurso sobre as ciências e as artes, resposta elaborada à questão da Academia de Dijon em 1750, se o restabelecimento das ciências e das artes teria contribuído para aprimorar os costumes, Rousseau responde negativamente e defende que as ciências, as artes e as letras contribuem para que os homens concorram entre si.

É dessa "concorrência" que nascem os refinamentos do gosto e da polidez. O homem polido, dotado de vontade de ser notório, apela para a adulação, para cuidados sedutores e traiçoeiros, e com o passar do tempo tem sua alma diminuída e o coração corrompido. O ciúme, a rivalidade e o ódio passam a permear ocultamente sob o véu da polidez as relações humanas, daí se justifica a condenação de Rousseau no Primeiro Discurso: "Não mais amizades sinceras e estima real; não mais confiança cimentada. As suspeitas, os receios, os medos, a frieza, a reserva, o ódio, a traição esconder-se-ão todo o tempo sob esse véu uniforme e pérfido da polidez (...)." ${ }^{\text {11 }}$

As ciências, as artes, o luxo, o comércio e as leis consideradas as obras primas da política pelos homens de letras, bem como as provas concretas da evolução e progressão da

${ }^{8}$ ROUSSEAU, Discurso sobre a origem e os fundamentos da desigualdade entre os homens, p. 260.

${ }^{9}$ SOUZA, Ilustração e bistória: o pensamento sobre a bistória no Iluminismo francês, p. 78.

${ }^{10}$ ROUSSEAU, Discurso sobre a origem e os fundamentos da desigualdade entre os homens, p. 263.

${ }^{11}$ ROUSSEAU, Discurso sobre as ciências e as artes, p. 344. 
sociedade, aparentam conceder amplos benefícios no que concerne aos laços dos homens ao pôr um dependente do outro mutuamente, criando necessidades recíprocas e interesses comuns, obrigando cada homem a concorrer à felicidade do outro para assim obter a sua.

Rousseau parece lamentar todas as relações humanas, pois apesar da ascensão triunfal das ciências e das artes na época das Luzes, as "disposições do coração" não correspondem mais à "atitude exterior", não há mais sinceridade, não existe mais confiança entre os homens. Segundo Jean Starobinski, o que está em jogo é o destino dos homens:

O espírito humano triunfa, mas o homem se perdeu. O contraste é violento, pois o que está em jogo não é apenas a noção abstrata do ser e do parecer, mas o destino dos homens, que se divide entre inocência renegada e a perdição doravante certa: o parecer e o mal são uma e mesma coisa. ${ }^{12}$

A história da humanidade que começou como a história da inocência, desenvolvese como a história da degeneração. Mas será possível um retorno à origem ou mesmo um encontro à redenção? No Prefácio a Narciso ou O amante de si mesmo, Rousseau ressalta que uma vez tendo acesso à corrupção, é impossível retornar à virtude. No máximo, podemos conservar os que ainda são virtuosos:

(...) em primeiro lugar, uma vez que um povo corrupto nunca mais volta à virtude, não se trata mais de tornar bons aqueles que não o são, mas de conservar assim aqueles que têm a felicidade de sê-lo. Em segundo lugar, as mesmas causas que corromperam os povos servem algumas vezes para prevenir uma corrupção ainda maior (....). ${ }^{13}$

Souza observa que ao contrário da concepção grega de história pensada a partir do modelo cósmico, isto é, a história da humanidade movendo-se em linhas circulares que se repetem, exibindo, portanto, um padrão repetitivo, a história em Jean-Jacques Rousseau baseia-se numa trajetória linear, cuja concepção é herdada da tradição cristã, sobretudo com Santo Agostinho na Cidade de Deus ao defender a volta de Cristo ressuscitado para acabar com todos os males do mundo:

Esse caráter da história que se poderia chamar de apocalíptico, que a divide num antes e num depois, um antes de estatuto prospectivo, que consiste numa preparação para o que virá no futuro, e um depois de caráter retrospectivo, dependendo do que se realizar agora, e que é a marca da

\footnotetext{
12 STAROBINSKI, Jean-Jacques Rousseau: a transparência e o obstáculo, p. 12.

${ }^{13}$ ROUSSEAU, Prefácio a Narciso ou O amante de si mesmo, p. 426.
} 
concepção linear moderna da história, parece ser uma herança laicizada do cristianismo. ${ }^{14}$

Porém, como ressalta a autora, a história linear de Rousseau não é a da redenção, mas a história da queda, "é como se ficássemos apenas com os momentos do paraíso e do pecado" $"$. Do lado do paraíso, temos o homem inocente em seu estado de natureza, livre e autossuficiente, cujas necessidades eram atendidas pela natureza. E, do outro lado, o do pecado, temos o homem corrompido e degenerado com suas novas necessidades, novos laços, movidos pela vaidade, pela inveja, pelo ciúme, enfim, pela vontade de ser visto pelo

outro. É esse o triste caminho da humanidade que Rousseau prevê em suas obras.

\section{HISTORY IN JEAN-JACQUES ROUSSEAU: THE DECAY OF NO RETURN}

Abstract: Since the Discourse on the Arts and Science, Rousseau points us to a history of societies when he negatively answers to the Academy of Dijon's question if the reestablishment of sciences and arts would have contributed to the enhancement of moral. In the Discourse on the Origin and Basis of Inequality Among Men, the philosopher discusses the history of mankind as a history of decay and degeneration, whereof is impossible to return to the original nature. The corruption in the societies may be retarded but never reversed. In other words, Rousseau presents a linear conception of history, which will be demonstrated in this essay through the interpretation of Maria das Graças de Souza.

Keywords: history - society - decay.

\section{REFERÊNCIAS BIBLIOGRÁFICAS}

ROUSSEAU, Jean-Jacques. Do contrato social; Ensaio sobre a origem das línguas; Discurso sobre a origem e os fundamentos da desigualdade entre os homens; Discurso sobre as ciências e as artes. Tradução: Lourdes Santos Machado; introdução e notas de Paulo Arbousse-Bastide e Lourival Gomes Machado. $1^{a}$ edição. Coleção Os Pensadores. São Paulo: Abril Cultural, 1973.

SOUZA, Maria das Graças de. Ilustração e história: o pensamento sobre a história no Iluminismo francês. São Paulo: Discurso Editorial, 2001.

STAROBINSKI, Jean. Jean-Jacques Rousseau: a transparência e o obstáculo. Tradução: Maria Lúcia Machado. Edição de bolso. São Paulo: Companhia das letras, 2011.

${ }^{14}$ SOUZA, Ilustração e história: o pensamento sobre a história no Iluminismo francês, p. 70.

15 SOUZA, Ilustração e história: o pensamento sobre a história no Iluminismo francês, p. 72. 